\title{
Poor glycated haemoglobin control and adverse pregnancy outcomes in type I and type 2 diabetes mellitus: Systematic review of observational studies
}

\author{
Melanie E Inkster*1, Tom P Fahey ${ }^{2}$, Peter T Donnan ${ }^{1}$, Graham P Leese ${ }^{3}$, \\ Gary J Mires ${ }^{4}$ and Deirdre J Murphy ${ }^{5}$
}

Address: ${ }^{1}$ Division of Community Health Sciences, University of Dundee, MacKenzie Building, Kirsty Semple Way, Dundee, UK, DD2 4BF, ${ }^{2}$ Department of General Practice, Royal College of Surgeons in Ireland, Mercer's Medical Centre, Stephen Street Lower, Dublin 2, Ireland, ${ }^{3}$ Diabetes Centre, Ninewells Hospital and Medical School, Dundee, UK, DD1 9SY, ${ }^{4}$ Maternal and Child Health Sciences, Ninewells Hospital and Medical School, Dundee, UK, DD1 9SY and ${ }^{5}$ Department of Obstetrics and Gynaecology, Trinity College, University of Dublin, Ireland

Email: Melanie E Inkster* - m.inkster@chs.dundee.ac.uk; Tom P Fahey - tomfahey@rcsi.ie; Peter T Donnan - p.t.donnan@chs.dundee.ac.uk; Graham P Leese - graham.leese@tuht.scot.nhs.uk; Gary J Mires - g.j.mires@dundee.ac.uk; Deirdre J Murphy - murphyd4@tcd.ie

* Corresponding author

Published: 30 October 2006

BMC Pregnancy and Childbirth 2006, 6:30 doi:10.1 186/1471-2393-6-30

This article is available from: http://www.biomedcentral.com/I47/-2393/6/30

(C) 2006 Inkster et al; licensee BioMed Central Ltd.

This is an Open Access article distributed under the terms of the Creative Commons Attribution License (http://creativecommons.org/licenses/by/2.0), which permits unrestricted use, distribution, and reproduction in any medium, provided the original work is properly cited.
Received: 24 March 2006
Accepted: 30 October 2006

\begin{abstract}
Background: Glycaemic control in women with diabetes is critical to satisfactory pregnancy outcome. A systematic review of two randomised trials concluded that there was no clear evidence of benefit from very tight versus tight glycaemic control for pregnant women with diabetes.

Methods: A systematic review of observational studies addressing miscarriage, congenital malformations and perinatal mortality among pregnant women with type I and type 2 diabetes was carried out. Literature searches were performed in MEDLINE, EMBASE, CINAHL and Cochrane Library. Observational studies with data on glycated haemoglobin $\left(\mathrm{HbA}_{\mathrm{Ic}}\right)$ levels categorised into poor and optimal control (as defined by the study investigators) were selected. Relative risks and odds ratios were calculated for $\mathrm{HbA}_{\mathrm{Ic}}$ and pregnancy outcomes. Adjusted relative risk estimates per I-percent decrease in $\mathrm{HbA}_{\mathrm{Ic}}$ were calculated for studies which contained information on mean and standard deviations of $\mathrm{HbA}_{\mathrm{Ic}}$.

Results: The review identified thirteen studies which compared poor versus optimal glycaemic control in relation to maternal, fetal and neonatal outcomes. Twelve of these studies reported the outcome of congenital malformations and showed an increased risk with poor glycaemic control, pooled odds ratio $3.44(95 \% \mathrm{Cl}, 2.30$ to 5.15$)$. For four of the twelve studies, it was also possible to calculate a relative risk reduction of congenital malformation for each I-percent decrease in $\mathrm{HbA}_{I c}$, these varied from 0.39 to 0.59 . The risk of miscarriage was reported in four studies and was associated with poor glycaemic control, pooled odds ratio $3.23(95 \% \mathrm{Cl}$, I.64 to 6.36$)$. Increased perinatal mortality was also associated with poor glycaemic control, pooled odds ratio $3.03(95 \% \mathrm{Cl}, \mathrm{I} .87$ to 4.92$)$ from four studies.
\end{abstract}

Conclusion: This analysis quantifies the increase in adverse pregnancy outcomes in women with diabetes who have poor glycaemic control. Relating percentage risk reduction in $\mathrm{HbA}_{\mathrm{Ic}}$ to relative risk of adverse pregnancy events may be useful in motivating women to achieve optimal control prior to conception. 


\section{Background}

Diabetes is the most common pre-existing medical condition complicating pregnancy in the United Kingdom (approximately four occurrences per 1000 pregnancies) [1]. It is known to have a substantial impact on maternal, fetal and neonatal outcomes. The presence of diabetes is said to increase the risk of congenital malformation (by ten-fold), the risk of stillbirth (by five-fold), and the risk of neonatal death (by three-fold) [2-7] These disappointing data are in contrast to the optimism of the 1989 St Vincent's Declaration that proposed as a five year target that the outcome of pregnancy should approximate that of the non-diabetic pregnancy [8].

A pivotal part of management is good diabetic control which is believed to reduce the incidence of pregnancy complications. Glycated haemoglobin $\left(\mathrm{HbA}_{1 \mathrm{c}}\right)$ reflects long-term glycaemic control and is a more accurate and stable measure than fasting blood glucose levels [9]. It tracks well over time in individuals with diabetes and has less variability than fasting blood glucose.

Longer term glycaemic control in women with diabetes is critical to satisfactory pregnancy outcome. As organogenesis takes place in the first trimester of pregnancy, inadequate pre-conceptual glycaemic control is associated with an increased risk of congenital abnormality and spontaneous abortion $[10,11]$.

Clinical management decisions are limited by a dearth of randomised trial data due to ethical reasons and current practice must rely on the findings of high quality observational studies.

The objective of the study was to perform a systematic review of observational studies to investigate and quantify the risk of adverse pregnancy outcomes in pregnant women with diabetes in relation to glycaemic control, whether poor or optimal.

\section{Methods \\ Study design}

We systematically reviewed observational studies of glycated haemoglobin and pregnancy outcomes in women with diabetes mellitus.

\section{Study selection}

We searched the MEDLINE database for articles published in English from 1966 to January 2005 by using Medical Subject Heading terms and text words related to pregnancy, diabetes mellitus, glycaemic control and glycated haemoglobin (Figure 1 contains the full text of the search strategy). We also searched EMBASE, CINAHL and the Cochrane Library.
We reviewed all abstracts obtained from our search for relevance. We manually reviewed bibliographies and review articles for additional citations and obtained the full text of potentially relevant articles.

Our pre-specified inclusion criteria were as follows: 1) published observational studies; 2 ) studies that examined pregnancy outcomes in women with type 1 and type 2 diabetes; and 3) studies that reported a measure of glycated haemoglobin and had clearly categorised pregnancy outcomes according to poor and optimal glycaemic control using a cut-off point. Case-control studies were included in the review only if there was clear distinction between optimal and poor glycaemic control in relation to outcomes in the cases (patients with diabetes). Control data from case-control studies were not used in this review. We excluded studies if they included women with gestational diabetes.

\section{Data abstraction}

One investigator reviewed each article that met the selection criteria and abstracted the data by using standardised data abstraction forms. Information was collected on study design, country of study, time-period of study, glycaemic control groups, method of measuring glycated haemoglobin, and timing of glycaemic control measurement. Data abstracted were age, parity, smoking, duration of diabetes, pre-pregnancy planning, folic acid consumption, presence of microvascular complications, pre-pregnancy insulin dose, sample size, type of outcome or outcomes, main results, statistical methods and variables, if any, which were included in the adjusted model or models.

For each study that met our inclusion criteria, we abstracted relative risks and odds ratios for the association between adverse pregnancy outcomes and poor vs. optimal glycaemic control if they were stated. If not, then the relative risks and odds ratios were calculated from information stated in each study.

A range of outcomes were investigated, however due to the quality of data we focussed on congenital malformations, miscarriage and perinatal mortality (including stillbirths and neonatal deaths).

A quality of reporting of meta-analyses of randomised controlled trials (QUOROM) checklist was carried out [see Additional file 1]. Quality assessment was modified to suit a meta-analysis of observational studies rather than randomized controlled trials, examining patient selection, data extraction methods, losses to follow up, and confounding. 


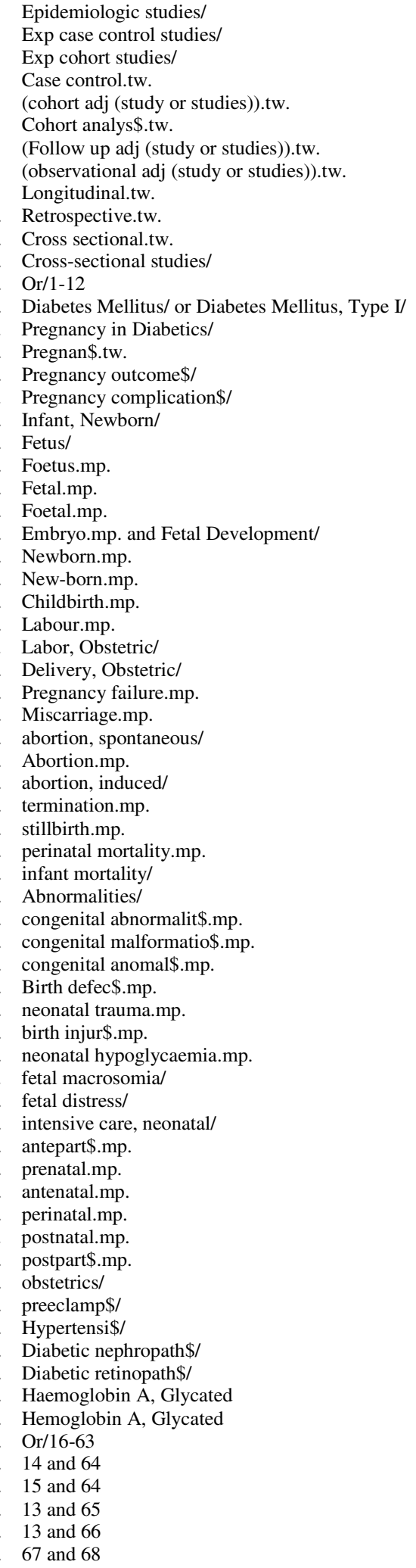

Figure I

Search strategy.

\section{Statistical analysis}

In the primary analysis, glycated haemoglobin $\left(\mathrm{HbA}_{1 \mathrm{c}}\right)$ was the principal 'exposure' of interest. $\mathrm{HbA}_{1 \mathrm{c}}$ was categorised into poor and optimal control. Dichotomous outcomes are expressed as odds ratios and 95\% confidence intervals are calculated. A test of heterogeneity, Cochran's Q-test, was performed for each outcome and if no heterogeneity was present, a fixed-effects meta-analysis was performed. If heterogeneity was marked, random effects models were performed.

For studies that reported the mean and SD of $\mathrm{HbA}_{1 \mathrm{c}}$ we estimated the effect of a 1-unit percent change in $\mathrm{HbA}_{1 \mathrm{c}^{\prime}}$ assuming a normal distribution for $\mathrm{HbA}_{1 \mathrm{c}}$ values. We calculated the $25^{\text {th }}$ and $75^{\text {th }}$ percentiles and divided the $\log$ relative risk by the difference of these 2 values to give an estimate of the effect of a 1-percent change in $\mathrm{HbA}_{1 \mathrm{c}}[12]$. We did not pool data from individual studies for these analyses as the measurement of $\mathrm{HbA}_{1 \mathrm{c}}$ differed between centres.

We assessed publication bias where possible by using the Egger test [13] and funnel plots which graphically display the magnitude of the effect estimate by the inverse variance of the study. Sensitivity analyses assessed the relative influence of each study by omitting one study at a time to assess the influence of the single study on the pooled estimate.

Statistical analyses were conducted using StatsDirect [14] and Stata Version 8 software.

\section{Results}

Search results

Our study identified 880 published studies from our search strategy. We retrieved the text of 256 and reviewed them to assess whether they provided information on $\mathrm{HbA}_{1 \mathrm{c}}$ and adverse pregnancy outcome in pregnant women with type 1 and type 2 diabetes. After we applied all exclusion and inclusion criteria, thirteen studies which compared poor vs. optimal glycaemic control in relation to maternal, fetal and neonatal outcomes, were included in this review, (Figure 2 contains the flow diagram of studies). Of these, eight were cohorts, two case-controls, one cross-sectional and two historical reviews.

\section{Qualitative summary}

Seven studies specifically looked at only women with Type 1 diabetes and the remaining six studies included both Type 1 and Type 2. Table 1 summarises the characteristics of all studies included in the analysis. Study populations were from United States, United Kingdom, Finland, France, Netherlands, Sweden and Poland. Sample sizes ranged from 83 to 2459 participants in the largest study, with a total of 5480 women. Most studies involved 


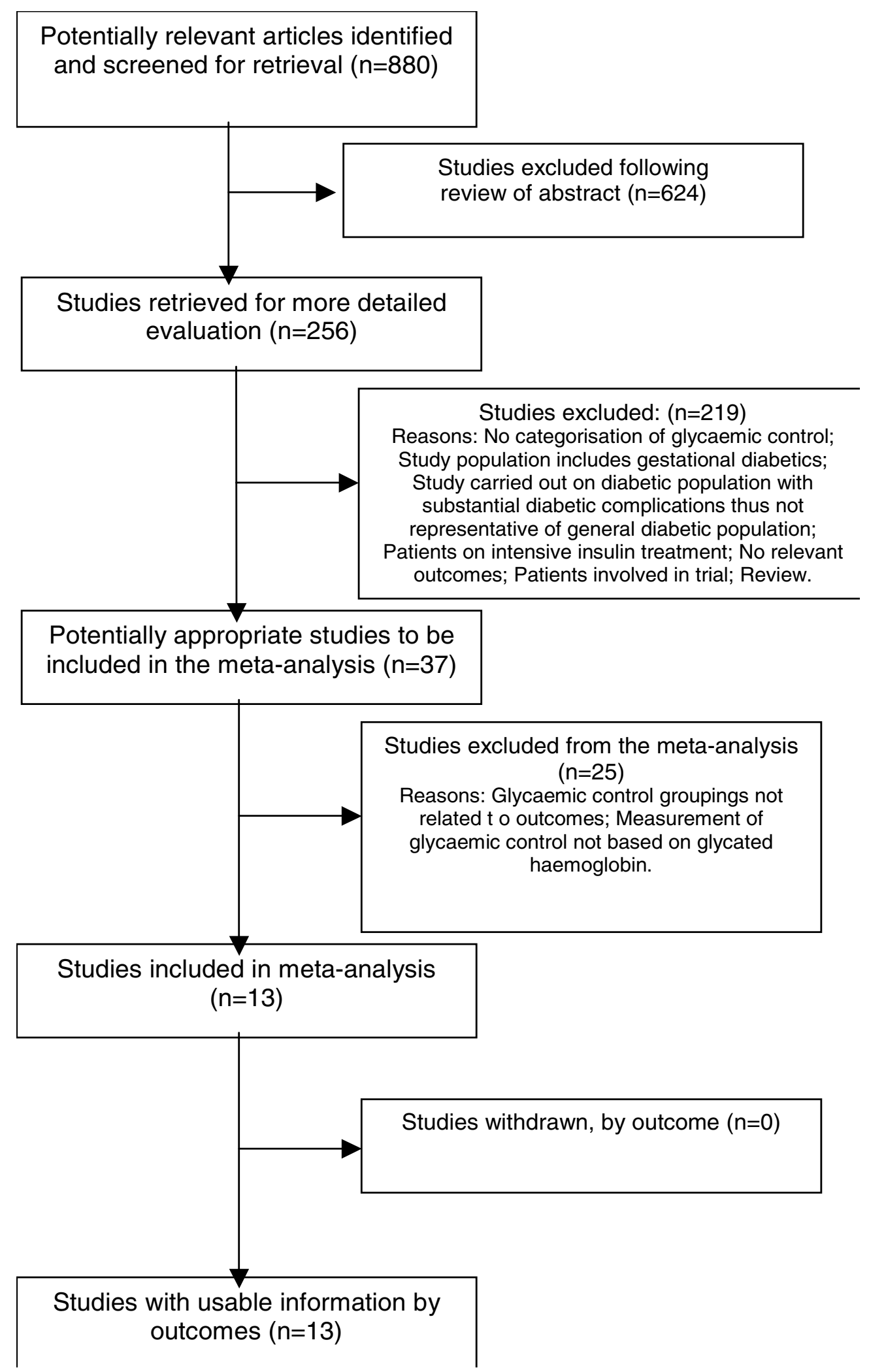

Figure 2

Flow of studies in the review. 
patients who were receiving pregnancy care at the study outpatient clinics. All studies described basic inclusion and exclusion criteria for study participants.

The method of measurement of $\mathrm{HbA}_{1 \mathrm{c}}$ varied across all the studies. Five studies used high-performance liquid chromatography $[7,15-18]$. Other methods used included spectrophotometric absorption, [19] column chromatography, [20] cation exchange method, [21] thiobarbituric acid colorimetric assay, [22] electrophoresis, [23] and isoelectric focusing [24]. Two of the studies did not give details on their method of measuring $\mathrm{HbA}_{1 \mathrm{c}}[25,26]$.

All studies used different cut-off points for grouping $\mathrm{HbA}_{1 \mathrm{c}}$ into poor and optimal groups, varying from 5.6\% to $10.1 \%$. The timing of the glycaemic control measurement varied across the studies, the majority of studies (twelve) measured $\mathrm{HbA}_{1 \mathrm{c}}$ during the first trimester. One study based glycaemic control on measurements taken at the first antenatal visit, $20^{\text {th }}$ and $28^{\text {th }}$ week of gestation, and just before delivery [26].

The data extraction method varied across the studies and very few studies $[15,17]$. adjusted for potential confounding factors in their analysis, (Table 2). Of these, neither stated what specific factors they adjusted for in the analysis.

\section{Quantitative summary}

The most common pregnancy outcome to be investigated was the outcome of congenital malformation, in which twelve out of the thirteen studies reported, (Table 3). Spontaneous abortions and perinatal mortality were reported in four of the studies, while all other maternal, fetal and neonatal outcomes in Table 3 were reported in only one of the studies.

The pooled estimate for patients with poor control and the outcome of congenital malformations was 3.44 (95\% CI, 2.30 to 5.15), (Figure 3). Six studies only reported major congenital malformations and the pooled estimate was 5.14 (95\% CI, 2.94 to 9.01), (Figure 4). It was possible to calculate a relative risk for each 1-percent point increase in $\mathrm{HbA}_{1 \mathrm{c}}$ for four out of the twelve studies which investigated the outcome of congenital malformations, these are presented in Table 4. The relative risk estimates varied from 1.63 to 2.34 per 1-percent point increase in $\mathrm{HbA}_{1 \mathrm{c}}$. These could be translated to a relative risk reduction per 1-percent point decrease in $\mathrm{HbA}_{1 \mathrm{c}}$ and varied from 0.39 to 0.59 .

The pooled estimate for the outcome of miscarriage was 3.23 (95\% CI, 1.64 to 6.36 ), (Figure 5) and for the outcome of perinatal mortality an odds ratio of 3.03 (95\% CI, 1.87 to 4.92 ), (Figure 6).
Sensitivity analyses indicated that three of the studies seemed to contribute more greatly to the analysis $[15,16,25]$. Sensitivity analyses, excluding the study with the largest number of participants [25], produced similar results.

\section{Publication bias}

A bias assessment plot for the outcome of congenital malformations is shown in Figure 7. The Egger test was not significant $(P>0.05)$ for the congenital malformation subgroup analysis. For the other outcomes however, the small number of studies limits our ability to draw conclusions regarding publication bias and heterogeneity of studies.

\section{Discussion}

In our analysis of thirteen published studies, adverse pregnancy outcomes were associated with higher levels of $\mathrm{HbA}_{1 \mathrm{c}}$ in women with type 1 and type 2 diabetes mellitus. These associations were present across different geographic populations and different time periods. A decrease in $\mathrm{HbA}_{1 \mathrm{c}}$ was associated with a clinically important reduction in the risk of fetal congenital malformations.

The outcome of congenital malformations was the most commonly reported outcome across the studies. Reasons for this may be because many clinical and epidemiological studies indicate that fetal malformations in pregnancy complicated by diabetes are due to metabolic disturbances affecting the process of organogenesis, which takes place at the early stage of pregnancy. The most common malformations in infants of mothers with diabetes are defects of the cardiovascular system. Studies suggest that these tissues are the most susceptible ones to the destructive action of oxygen-free radicals [20]. Our analysis shows that poor glycaemic control is associated with a greater than three-fold risk for the outcome of congenital malformations compared to optimal glycaemic control. The rates of miscarriage and perinatal mortality were higher in the poor glycaemic control groups compared with the optimal control groups. Perinatal mortality rates have markedly decreased over the last 25 years, however there still appears to be a higher rate of perinatal mortality with poorer levels of glycaemic control.

There are limited randomised trial data on the impact of different levels of glycaemic control on outcome in diabetic pregnancies [27]. The randomised, prospective Diabetes Control and Complications Trial (DCCT) has shown that timely institution of intensive therapy for blood glucose control is associated with rates of spontaneous abortion and congenital malformations that are similar to those in the non-diabetic populations [28]. A Cochrane systematic review of randomised trials compar- 
Table I: Design characteristics of observational studies of glycated haemoglobin and pregnancy outcomes.

\begin{tabular}{|c|c|c|c|c|c|c|c|}
\hline Author & Country & Study Design & Time Period & $\underset{(n)}{\text { Sample size }}$ & $\begin{array}{l}\text { Glycaemic Control Groupings } \\
\text { (n) (HbA Ic unless stated) }\end{array}$ & $\begin{array}{l}\text { Timing of Glycaemic } \\
\text { Control Measurement }\end{array}$ & Outcomes (n) \\
\hline Vaarasmaki et al, 2000 [26] & Finland & Cohort & $1986-1995$ & 84 & $\begin{array}{l}\text { Optimal }<8.0 \%(n=48) \\
\text { Poor }>8.0 \%(n=36)\end{array}$ & $\begin{array}{l}\text { First antenatal visit } 20 \text { and } \\
28^{\text {th }} \text { week Before delivery }\end{array}$ & $\begin{array}{c}\text { Malformations }(n=4) \\
\text { Caesarean section }(n=34) \\
\text { Stillbirth }(n=1) \\
\text { NICU }(n=39) \\
\text { Neonatal hypoglycaemia }(n=11) \\
\operatorname{RDS}(n=5)\end{array}$ \\
\hline Greene et al, 1989 [23] & US & Cohort & Dec.5th | 983-Dec.3 |st | 987 & 303 & $\begin{array}{c}\text { Optimal } \leq 9.3 \%(n=113) \\
\text { Poor } \geq 9.4 \%(n=190) \\
\left.\text { (Data based on } \mathrm{HbA} \mathrm{A}_{1}\right)\end{array}$ & Ist trimester & $\begin{array}{l}\text { Malformations }(n=20) \\
\text { Spontaneous abortion }(n=52)\end{array}$ \\
\hline Evers et al, 2004 [16] & Netherlands & Cohort & April |st | 999 - April |st 2000 & 261 & $\begin{array}{c}\text { Optimal } \leq 7.0 \%(n=212) \\
\text { Poor } \geq 7.0 \%(n=7 \mid)\end{array}$ & Ist trimester & Malformations $(n=29)$ \\
\hline Key et al, 1987 [19]. & US & Cohort & Jan. | Ist 1979 - Dec.3 | st $^{\text {st }} 984$ & 83 & $\begin{array}{l}\text { Optimal }<7.5 \%(n=8) \\
\text { Poor } \geq 7.5 \%(n=75)\end{array}$ & Ist trimester & $\begin{array}{l}\text { Malformations }(n=9) \\
\text { Spontaneous abortion }(n=22)\end{array}$ \\
\hline Temple et al, 2002 [7] & UK & Cohort & Jan. 199|-Dec. 2000 & 158 & $\begin{array}{c}\text { Optimal }<7.5 \%(n=110) \\
\text { Poor } \geq 7.5 \%(n=48)\end{array}$ & Ist trimester booking & $\begin{array}{c}\text { Malformations }(n=5) \\
\text { Stillbirth }(n=2) \\
\text { Spontaneous abortion }(n=11) \\
\text { Neonatal death }(n=2)\end{array}$ \\
\hline Kitzmiller et al, 1991 [22] & USA & Cohort & $1982-1988$ & 194 & $\begin{array}{l}\text { Optimal } \leq 7.6 \%(n=53) \\
\text { Poor }>7.6 \%(n=141)\end{array}$ & Ist trimester booking visit & Malformations $(n=13)$ \\
\hline Ylinen et al, 1984 [2I] & Finland & Cohort & April 1978-Dec. 1982 & 142 & $\begin{array}{c}\text { Optimal } \leq 7.9 \%(n=63) \\
\text { Poor }>7.9 \%(n=79)\end{array}$ & Before 16 weeks gestation & Malformations $(n=17)$ \\
\hline CEMACH, 2005 [25] & $\begin{array}{l}\text { England, Wales \& } \\
\text { Northern Ireland }\end{array}$ & $\begin{array}{l}\text { Descriptive } \\
\text { Cohort }\end{array}$ & March Ist 2002-Feb 28 2003 & 2459 & $\begin{array}{l}\text { Optimal }<7 \%(n=962) \\
\text { Poor } \geq 7 \%(n=1497)\end{array}$ & Ist trimester & $\begin{array}{l}\text { Malformations }(n=101) \\
\text { Stillbirths or neonatal deaths }(n=67)\end{array}$ \\
\hline Hiilesmaa et al, 2000 [17] & Finland & Case-Control & $1988-1997$ & 587 & $\begin{array}{l}\text { Optimal } \leq 6.8 \%(n=195) \\
\text { Poor }>6.8 \%(n=392)\end{array}$ & Early pregnancy & $\begin{array}{c}\text { Pre-eclampsia }(n=77) \\
\operatorname{PIH}(n=65)\end{array}$ \\
\hline Hanson et al, 1990 [24] & Sweden & Case-Control & $1982-1985$ & 532 & $\begin{array}{c}\text { Optimal }<10.1 \%(n=490) \\
\text { Poor } \geq 10.1 \%(n=42)\end{array}$ & Ist trimester & $\begin{array}{l}\text { Spontaneous abortion }(n=4 I) \\
\text { Malformation }(n=21)\end{array}$ \\
\hline $\begin{array}{l}\text { Diabetes and Pregnancy Group, France } \\
\qquad 2003[15]\end{array}$ & France & Cross-sectional & Jan. 2000 - Dec. 2001 & 435 & $\begin{array}{l}\text { Optimal }<8.0 \%(n=315) \\
\text { Poor }>8.0 \%(n=120)\end{array}$ & Ist trimester & $\begin{array}{l}\text { Malformations }(n=18) \\
\text { Perinatal mortality }(n=19) \\
\text { Preterm delivery }(n=147)\end{array}$ \\
\hline Miller et al, 198। [18] & US & Case-series & April 1977 - April 1980 & 116 & $\begin{array}{l}\text { Optimal } \leq 8.5 \%(n=58) \\
\text { Poor } \geq 8.6 \%(n=58)\end{array}$ & Initial value & Malformations $(n=15)$ \\
\hline Wender-Ozegowska et al, 2005 [20] & Poland & Case-Series & | st Jan. 1994-3|st Jan. 1999 & 126 & $\begin{array}{l}\text { Optimal } \leq 5.6 \%(n=43) \\
\text { Poor }>5.6 \%(n=83)\end{array}$ & Ist trimester & Malformations $(n=14)$ \\
\hline
\end{tabular}


Table 2: Quality assessment of included studies.

\begin{tabular}{|c|c|c|c|c|c|c|c|c|c|c|c|c|c|}
\hline Authors Reference & 26 & 23 & 16 & 19 & 7 & 22 & 21 & 25 & 17 & 24 & 15 & 18 & 20 \\
\hline Is the hypothesis clearly defined & $\mathrm{Y}$ & $\mathrm{Y}$ & $\mathrm{Y}$ & $\mathrm{Y}$ & $\mathrm{Y}$ & Y & Y & $\mathrm{Y}$ & $\mathrm{Y}$ & Y & $\mathrm{Y}$ & $\mathrm{Y}$ & $\mathrm{Y}$ \\
\hline Inclusion criteria defined & Y & Y & Y & Y & $\mathrm{N}$ & Y & Y & Y & Y & Y & Y & Y & Y \\
\hline Method of sample selection stated & Y & Y & Y & Y & $Y$ & Y & Y & $Y$ & Y & Y & Y & Y & Y \\
\hline Data extraction method stated & Y & Y & Y & Y & $\mathrm{N}$ & Y & Y & Y & Y & Y & Y & Y & Y \\
\hline Adequate description of diagnostic criteria & $Y$ & Y & Y & Y & $\mathrm{N}$ & Y & Y & $Y$ & Y & Y & Y & $\mathrm{N}$ & Y \\
\hline Clinical and demographic characteristics fully defined & Y & Y & Y & Y & Y & Y & Y & Y & Y & Y & Y & Y & Y \\
\hline Complete and representative sample of patients & Y & Y & Y & Y & Y & Y & Y & Y & Y & Y & Y & Y & Y \\
\hline Appropriate follow-up of patients & $Y$ & Y & Y & Y & $Y$ & Y & Y & $Y$ & Y & Y & $Y$ & Y & Y \\
\hline Losses to follow up & $\mathrm{N}$ & Y & Y & Y & $\mathrm{N}$ & Y & NA & $\mathrm{N}$ & NA & Y & NA & NA & NA \\
\hline Unbiased outcome & Y & Y & Y & Y & Y & Y & Y & Y & Y & Y & Y & Y & Y \\
\hline Fully defined outcome & $Y$ & $Y$ & Y & $\mathrm{N}$ & $\mathrm{N}$ & Y & Y & $Y$ & Y & Y & Y & Y & $\mathrm{N}$ \\
\hline Appropriate outcome & $Y$ & $Y$ & Y & $Y$ & $Y$ & Y & Y & $Y$ & Y & Y & Y & Y & Y \\
\hline Outcome known for all or a high proportion of patients & $Y$ & $Y$ & Y & Y & Y & Y & Y & $Y$ & Y & Y & Y & Y & Y \\
\hline Fully defined prognostic variable & Y & Y & Y & Y & Y & Y & Y & Y & Y & Y & Y & Y & Y \\
\hline $\begin{array}{l}\text { Prognostic variable available for all or a high proportion of } \\
\text { patients }\end{array}$ & $\mathrm{N}$ & Y & Y & Y & Y & Y & Y & $\mathrm{N}$ & Y & Y & Y & Y & Y \\
\hline Continuous predictor variable analysed appropriately & Y & Y & Y & Y & Y & Y & Y & Y & Y & Y & Y & Y & Y \\
\hline Statistical adjustment for all important prognostic variables & $\mathrm{N}$ & $\mathrm{N}$ & $\mathrm{N}$ & $\mathrm{N}$ & $\mathrm{N}$ & $\mathrm{N}$ & $\mathrm{N}$ & NA & Y & $\mathrm{N}$ & Y & $\mathrm{N}$ & $\mathrm{N}$ \\
\hline
\end{tabular}

ing very tight with tight control of diabetes in pregnancy focused on two trials involving a total of 182 women. The conclusion was that there was no clear evidence of benefit from very tight versus tight glycaemic control for pregnant women with diabetes [27]. Observational studies show much less favourable outcomes in unselected populations. In many studies, adverse outcomes remain more common among the infants of mothers with type 1 diabetes than in the general population $[8,29]$. The targets of the St. Vincent's Declaration of 1989 appear not to have been met, thus far. Reasons for persistently poor outcomes in these populations may include unplanned pregnancies, pregnancies in women who have not received pre-conceptual care, or pregnancies in women who fail to achieve optimal control despite adequate pre-conceptual care.

The factors that influence women to seek preconception care and counselling and then to actually achieve optimal glycaemic control prior to conception have become important to clinicians. Factors that seem to promote preconception care include higher educational levels, higher incomes, regular employment, and receiving encouragement from their health care providers to avoid unplanned pregnancies [30]. Past pregnancy experience may also play a role through influencing behaviour concerning diabetic control and health habits [31].

A systematic review of 14 cohort studies has shown that pre-conception care aiming to achieve tight glycaemic control is associated with a reduction in the rate of major congenital abnormalities $-2.1 \%$ in the preconception care recipients versus $6.5 \%$ in non recipients, relative risk $0.36,95 \%$ CI 0.22 to 0.59 [32].

Patients who frequently monitor and adjust their diabetes regimen are more likely to maintain strict control of their blood glucose levels throughout pregnancy [33]. Our

Table 3: Pregnancy outcomes and number of studies included in review reporting outcome.

\begin{tabular}{cc}
\hline Outcome & No. of studies reporting outcomes \\
\hline Congenital malformations & 12 \\
Spontaneous abortions & 4 \\
Perinatal mortality & 4 \\
Neonatal deaths & 1 \\
Preterm delivery & 1 \\
Neonatal hypoglycaemia & 1 \\
Neonatal Intensive Care Unit Admission & 1 \\
Respiratory Distress Syndrome & 1 \\
Caesarean Section & 1 \\
Pre-eclampsia & 1 \\
Pregnancy-induced hypertension &
\end{tabular}




\section{Odds ratio meta-analysis plot [random effects]}

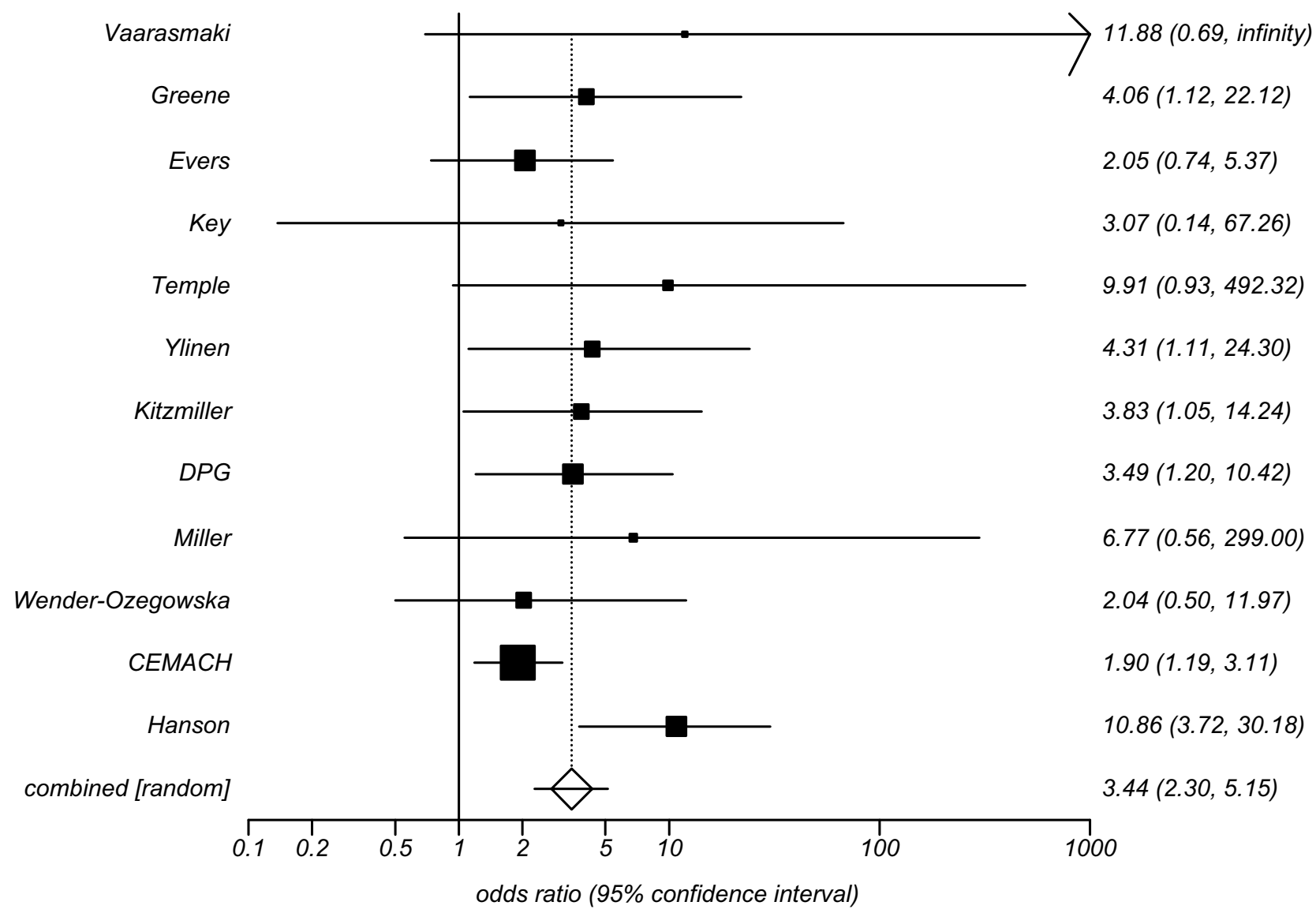

Figure 3

Risk of congenital malformation for poor versus optimal glycaemic control. Pooled odds ratio $=3.44(95 \% \mathrm{Cl}=$ 3.00 to 5.I5). $\mathrm{Chi}^{2}$ (test odds ratio differs from I) $=36.2(\mathrm{df}=\mathrm{I}) \mathrm{P}<0.00 \mathrm{I}$.

findings support this with a marked increase in congenital malformation in association with poor glycaemic control. A decremental approach to $\mathrm{HbA}_{1 \mathrm{c}}$ may appeal to women who are overwhelmed at the prospect of achieving a dramatic change in control from poor to optimal. Advising women that there is a potential health gain with each $1 \%$ reduction may be a useful motivator in gradual reduction to an optimal level or may provide some reassurance for women who manage a large improvement but do not quite achieve optimal levels.

This review has several limitations. It is unclear to what extent methodologic limitations, such as residual confounding and selection bias, might exist in these studies. The pooled odds ratios have been used to quantify the risks, however the small number of studies meant that statistical analyses for heterogeneity and publication bias were limited. Although the funnel plot for the outcome of congenital malformation shows an indication of asymmetry, with just twelve studies the power to detect asymmetry in a funnel plot is low. Thus, we cannot make any conclusions about publication bias and we cannot exclude the possibility that the observed association is a result of publication bias. We believe our process of literature identification was comprehensive and captured all of the published studies on the relation between $\mathrm{HbA}_{1 \mathrm{c}}$ and outcomes in pregnant women with diabetes.

The studies use different definitions of poor and optimal control, ranging from $5.6 \%$ to $10.1 \%$. Reasons for this include the use of different methods of measurements for $\mathrm{HbA}_{1 \mathrm{c}}$ and varying reference ranges for the non-diabetic population. Nonetheless, the cut-offs used were appropriate to the method used to measure $\mathrm{HbA}_{1 \mathrm{c}}$ and relevant to 


\section{Odds ratio meta-analysis plot [random effects]}

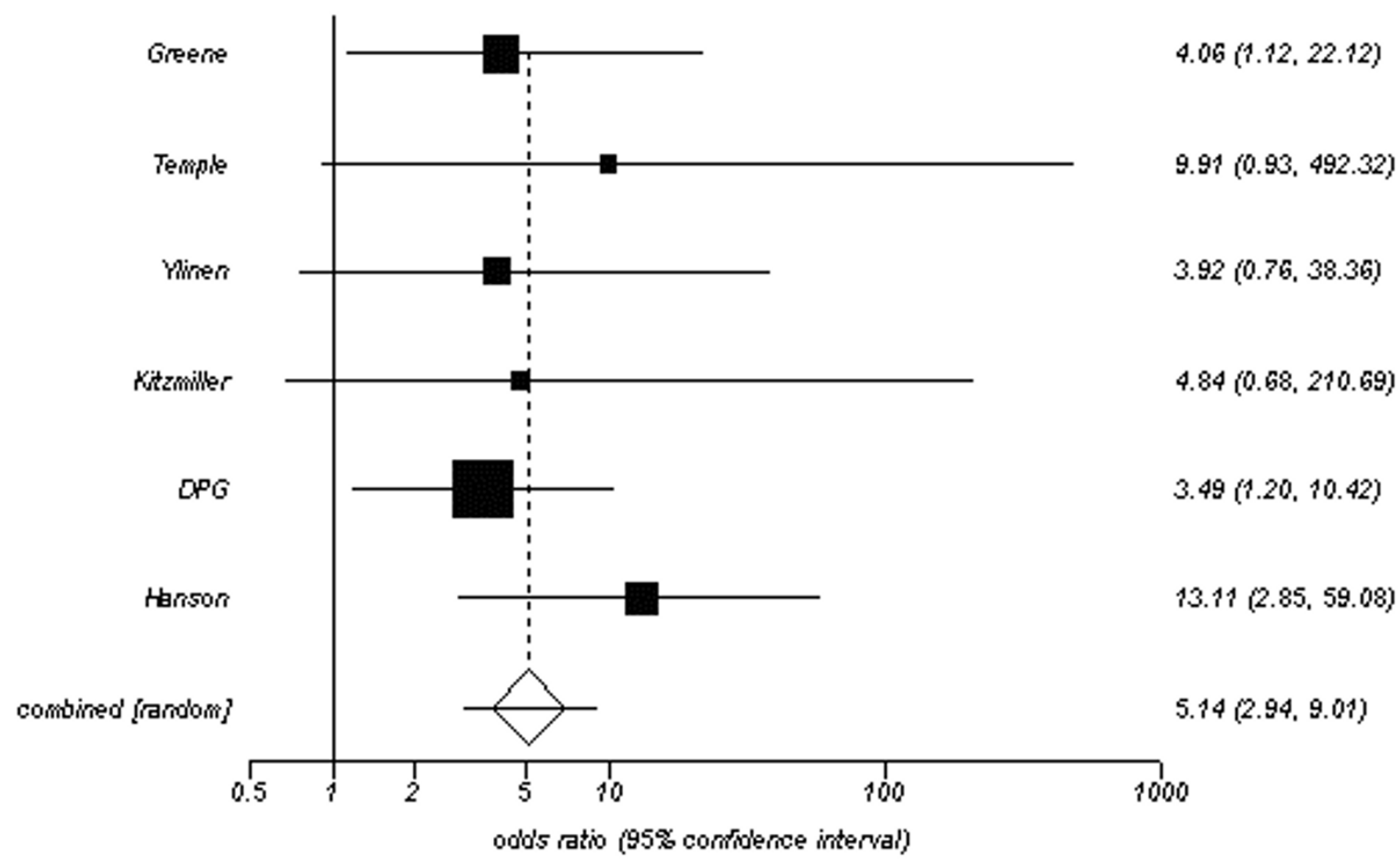

Figure 4

Risk of major congenital malformation for poor versus optimal glycaemic control. Pooled odds ratio $=5.14(95 \%$ $\mathrm{Cl}=3.00$ to $9.0 \mathrm{I})$. Chi' ${ }^{2}$ (test odds ratio differs from I) $=32.8(\mathrm{df}=\mathrm{I}) \mathrm{P}<0.00 \mathrm{I}$.

the reference range in use for the individual study populations. For this reason it would have been inappropriate to do a subgroup analysis using different cut-off levels as categories.

Definitions for several of the outcomes varied across the studies, for example, the outcome of congenital malformations included both major and minor malformations in some studies $[16,26]$ while in others only included major malformations $[7,18]$.

Few studies adjusted for confounding factors in their analysis and there is no certainty that the observed association was caused exclusively by an elevated $\mathrm{HbA}_{1 \mathrm{c}}$ level rather than to some degree by related confounders. In the majority of the studies we do not know how advanced the patients' diabetes was. Diabetic nephropathy and retinop-

Table 4: Relative risk estimates per I-percentage point increase in glycated haemoglobin and the outcome of congenital malformation.

\begin{tabular}{|c|c|c|c|c|c|c|c|c|}
\hline Author & Mean & SD & $25^{\text {th }}$ percentile & $75^{\text {th }}$ percentile & $\begin{array}{c}\text { Difference between } \\
25^{\text {th }} \text { and } 75^{\text {th }} \\
\text { percentile }\end{array}$ & $\begin{array}{l}\text { Inverse } \\
\text { Relative } \\
\text { Risk }\end{array}$ & $\begin{array}{l}\text { Relative Risk per } \\
\text { I\% point increase }\end{array}$ & $\begin{array}{l}\text { Relative Risk per } \\
\text { I \% point decrease }\end{array}$ \\
\hline Miller [18] & 8.54 & 1.54 & 7.50 & 9.58 & 2.08 & I.87 & 2.34 & 0.59 \\
\hline Greene [23] & 10.10 & 1.99 & 8.76 & II.44 & 2.68 & $\mid .31$ & 1.63 & 0.39 \\
\hline Evers [16] & 6.5 & 0.70 & 6.03 & 6.97 & 0.94 & 0.65 & 1.99 & 0.50 \\
\hline Key [19] & 10.99 & 1.10 & 10.25 & 11.73 & 1.48 & 1.0 & 1.95 & 0.49 \\
\hline
\end{tabular}


Odds ratio meta-analysis plot [random effects]

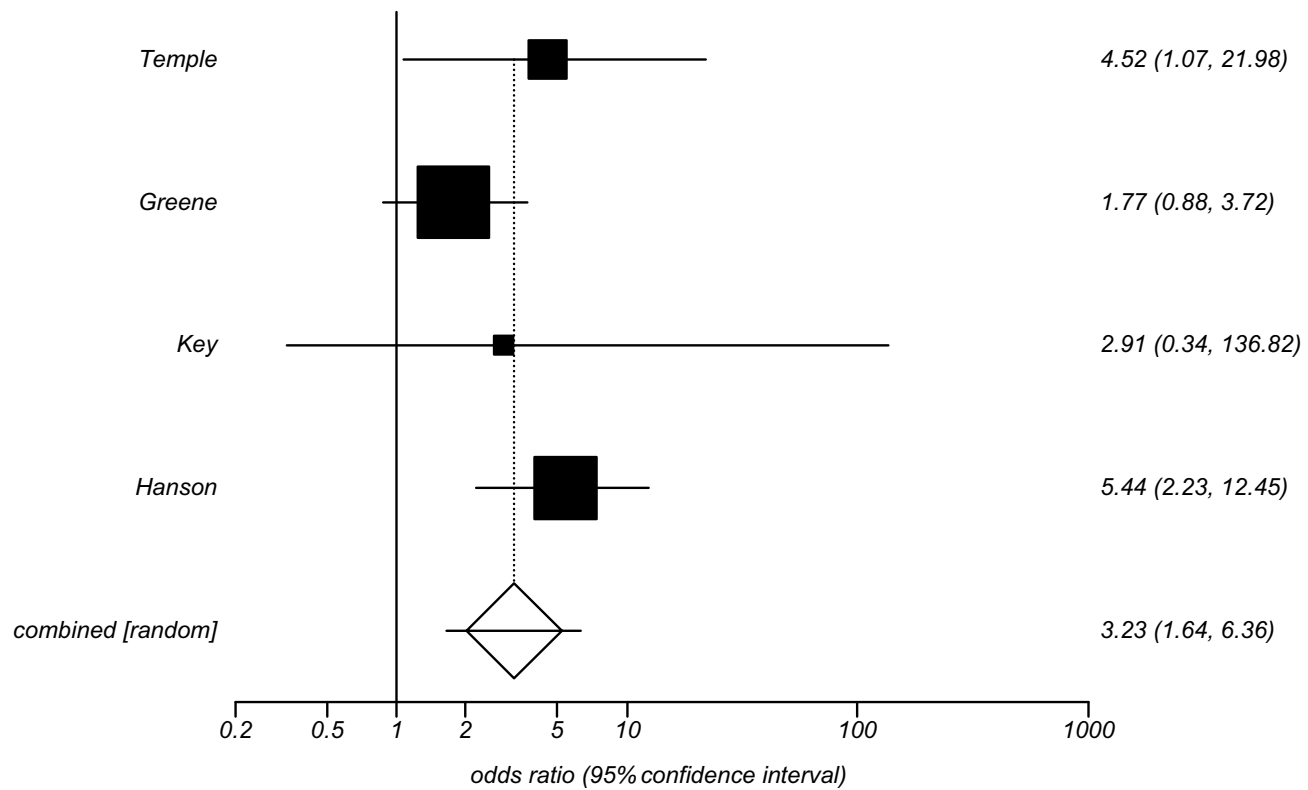

Figure 5

Risk of miscarriage for poor versus optimal glycaemic control. Pooled odds ratio $=3.23(95 \% \mathrm{Cl}=1.64$ to 6.36$)$. Chi ${ }^{2}$ (test odds ratio differs from $\mathrm{I})=\mathrm{II} .48(\mathrm{df}=\mathrm{I}) \mathrm{P}=0.00 \mathrm{I}$.

Odds ratio meta-analysis plot [random effects]

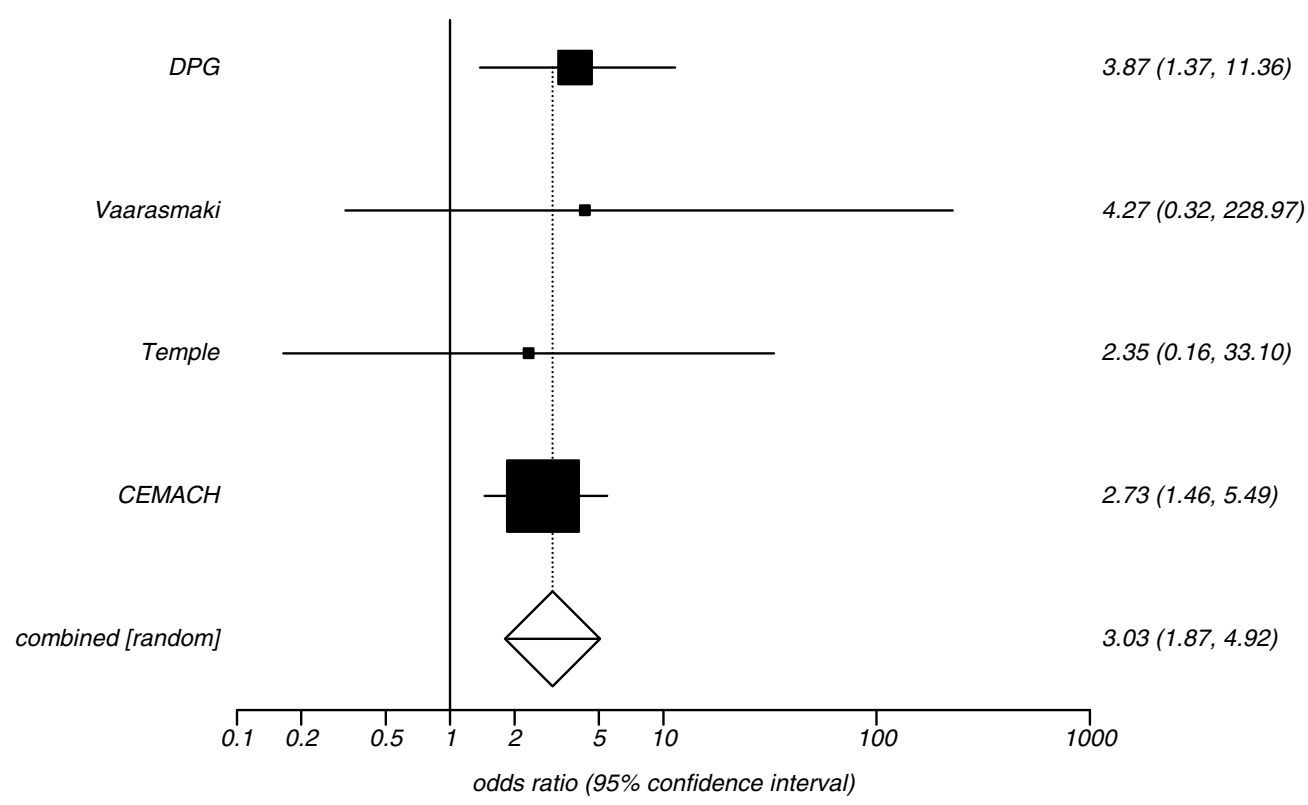

Figure 6

Risk of perinatal mortality for poor versus optimal glycaemic control. Pooled odds ratio $=3.03(95 \% \mathrm{Cl}=1.87$ to 4.92). Chi ${ }^{2}$ (test odds ratio differs from I) $=20.13(d f=I) P<0.000 I$. 


\section{Bias assessment plot}

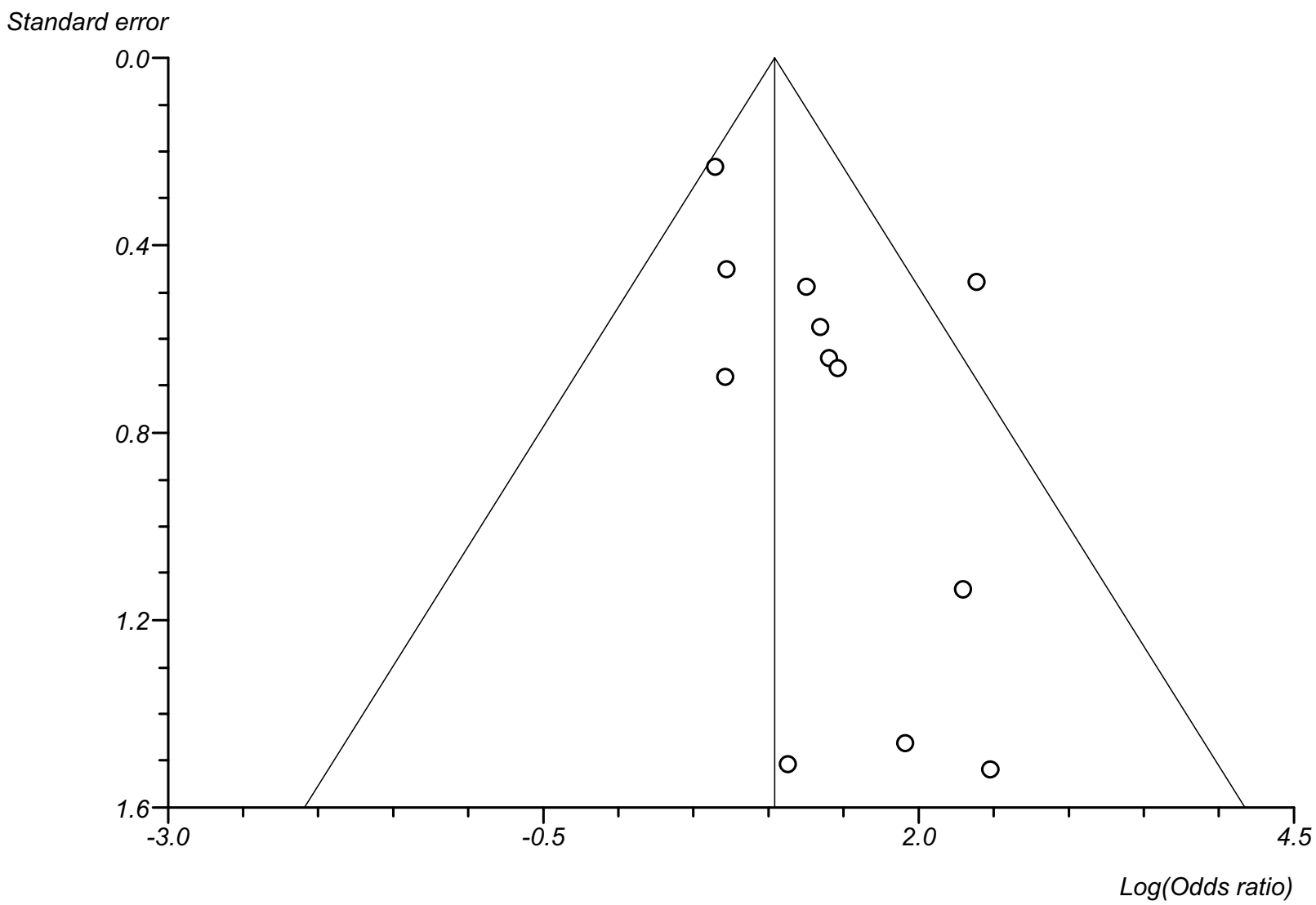

\section{Figure 7}

Bias assessment plot for the outcome of congenital malformations. Begg-Mazumdar: Kendall's tau $=0.33 \mathrm{P}=0.15$. Egger: bias $=1.27(95 \% \mathrm{Cl}=-0.0 \mathrm{I}$ to 2.56$) \mathrm{P}=0.05$. Horbold-Egger: bias $=2.19(95 \% \mathrm{Cl}=0.53$ to 3.84$) \mathrm{P}=0.03$.

athy are the most frequent complications in patients of childbearing age with diabetes and will have an important impact on pregnancy outcome [34]. One possible causal factor for adverse outcome could be women with established diabetes complications, such as microvascular disease. A single unsatisfactory $\mathrm{HbA}_{1 \mathrm{c}}$ value cannot be used as an absolute predictor of fetal outcome, but it indicates a subgroup of pregnancies with substantial fetal risk [26].

Major advantages of pooling data from observational studies to investigate this important clinical issue are better generalisability because the analyses combine data from heterogeneous populations, and increased sample size.

\section{Conclusion}

Our systematic review highlights important weaknesses in the literature. Studies to date are based on very small numbers and this systematic review allows more robust estimate of risk. Many important clinical outcomes were not examined in the thirteen studies included in the review. More than a decade after the initial evidence proposing that pregnancy outcome was improved by better glycaemic control, the question of how strict that control should be remains unanswered. There remains an urgent need to address the maternal and perinatal benefits of varying degrees of control of blood sugar for pregnant women with diabetes. Outcome measures should be standardised and include important factors associated with poor perinatal and maternal outcomes, such as preeclampsia, macrosomia, caesarean section, shoulder dystocia, perinatal loss, neonatal respiratory and metabolic complications [27]. Future studies also need to investigate the issue of pre-conceptual glycaemic control and post pregnancy outcomes for the mother. We are currently undertaking a study exploring the related issues of pre- 
conceptual glycaemic control, antenatal care, and mode of delivery in terms of pregnancy-related, maternal and neonatal outcomes both in the short- and long-term.

We conclude that adverse pregnancy outcomes in women with type 1 and type 2 diabetes mellitus were associated with higher levels of $\mathrm{HbA}_{1 \mathrm{c}}$. This review summarises the currently available evidence and should be useful to clinicians who are counselling women with type 1 and type 2 diabetes in the reproductive years.

\section{Competing interests}

The author(s) declare that they have no competing interests.

\section{Authors' contributions}

MEI, TPF and DJM conceived the review, MEI reviewed and analysed the data and wrote the review. All authors interpreted the data, contributed to writing the manuscript, and gave critical comments. All authors have given approval of the final version to be published.

\section{Additional material}

\section{Additional file 1}

QUORUM statement.

Click here for file

[http://www.biomedcentral.com/content/supplementary/14712393-6-30-S1.pdf]

\section{Acknowledgements}

Funding was provided by Chief Scientist Office, Scottish Executive Health Department in the form of a Research Training Fellowship in Health Services Research held by M E Inkster.

\section{References}

I. Hawthorne G, Modder J: Maternity Services for Women With Diabetes in the UK. Diabetic Medicine 2002, I 9(Suppl 4):50-5.

2. Casson IF, Clarke CA, Howard CV, McKendrick O, Pennycook S, Pharoah PO, Platt MJ, Stanisstreet M, van Velszen D, Walkinshaw S: Outcomes of Pregnancy in Insulin Dependent Diabetic Women: Results of a Five Year Population Cohort Study. BMJ 3 I 5:275-8. 2-8-1997

3. Hawthorne G, Robson S, Ryall EA, Sen D, Roberts SH, Ward Platt MP: Prospective Population Based Survey of Outcome of Pregnancy in Diabetic Women: Results of the Northern Diabetic Pregnancy Audit, I 994. BM] 3 I 5:279-8I. 2-8-1997

4. Hawthorne G, Irgens LM, Lie RT: Outcome of Pregnancy in Diabetic Women in Northeast England and in Norway, 1994-7. BM] 32 1:730-I. 23-9-2000

5. Janz NK, Herman WH, Becker MP, Charron-Prochownik D, Shayna VL, Lesnick TG, Jacober SJ, Fachnie JD, Kruger DF, Sanfield JA: Diabetes and Pregnancy. Factors Associated With Seeking PreConception Care. Diabetes Care 1995, I8(2): I57-65.

6. Martin FIR, Heath P, Mountain KR: Pregnancy in Women With Diabetes Mellitus. Fifteen Years' Experience: I970-I985. Medical Journal of Australia 1987, I46(4):

7. Temple R, Aldridge V, Greenwood R, Heyburn P, Sampson M, Stanley K: Association Between Outcome of Pregnancy and Glycaemic Control in Early Pregnancy in Type I Diabetes: Population Based Study. BMJ 2002, 325:1275-6.
8. Platt MJ: St Vincent's Declaration 10 Years on: Outcomes of Diabetic Pregnancies. Diabetic Medicine 2002, I 9(3):2 I6-20.

9. Goldstein DE, Little RR, Lorenz RA, Malone JI, Nathan D, Peterson CM, Sacks DB: Tests of Glycemia in Diabetes. Diabetes Care 2004, 27(7): | 76I-73.

10. Rosenn B, Miodovnik M, Dignan PS, Siddiqi TA, Khoury J, Mimouni F: Minor Congenital Malformations in Infants of InsulinDependent Diabetic Women: Association With Poor Glycemic Control. Obstetrics \& Gynecology 1990, 76(5 Pt I):745-9.

II. Rosenn B, Miodovnik M, Combs CA, Khoury J, Siddiqi TA: Glycemic Thresholds for Spontaneous Abortion and Congenital Malformations in Insulin-Dependent Diabetes Mellitus. Obstetrics \& Gynecology 1994, 84(4):5 I5-20.

12. Greenland S: Quantitative Methods in the Review of Epidemiologic Literature. Epidemiologic Reviews 1987, 9: I-30.

13. Egger M, Davey, Smith G, Schneider M, Minder C: Bias in MetaAnalysis Detected by a Simple, Graphical Test. BMJ 1997 , 3 15:629-34.

14. StatsDirect Statistical Software [http://www.statsdirect.com]

15. Gestation and Diabetes in France Study Group: Multicenter Survey of Diabetic Pregnancy in France. Gestation and Diabetes in France Study Group. Diabetes Care I99I, I4(I I):994-I000.

16. Evers IM, de Valk HW, Visser GH: Risk of Complications of Pregnancy in Women With Type I Diabetes: Nationwide Prospective Study in the Netherlands. BMJ 2004, 328:915.

17. Hiilesmaa V, Suhonen L, Teramo K: Glycaemic Control Is Associated With Pre-Eclampsia but Not With Pregnancy-Induced Hypertension in Women With Type I Diabetes Mellitus. Diabetologia 2000, 43(I 2): I534-9.

18. Miller E, Hare JW, Cloherty JP, Dunn PJ, Gleason RE, Soeldner JS, Kitzmiller JL: Elevated Maternal Hemoglobin Alc in Early Pregnancy and Major Congenital Anomalies in Infants of Diabetic Mothers. New England Journal of Medicine I98I, 304(22): $|33|-4$

19. Key TC, Giuffrida R, Moore TR: Predictive Value of Early Pregnancy Glycohemoglobin in the Insulin-Treated Diabetic Patient. American Journal of Obstetrics \& Gynecology 1987, I 56(5): 1096-100

20. Wender-Ozegowska E, Wroblewska K, Zawiejska A, Pietryga M, Szczapa J, Biczysko R: Threshold Values of Maternal Blood Glucose in Early Diabetic Pregnancy - Prediction of Fetal Malformations. Acta Obstetricia et Gynecologica Scandinavica 2005, 84(I): I 7-25.

21. Ylinen K, Aula P, Stenman UH, Kesaniemi-Kuokkanen T, Teramo K: Risk of Minor and Major Fetal Malformations in Diabetics With High Haemoglobin A I c Values in Early Pregnancy. British Medical Journal Clinical Research Ed I984, 289(644I):345-6.

22. Kitzmiller JL, Gavin LA, Gin GD, Jovanovic-Peterson L, Main EK, Zigrang WD: Preconception Care of Diabetes. Glycemic Control Prevents Congenital Anomalies. JAMA 265(6):73 I-6. I3-2|99|

23. Greene MF, Hare JW, Cloherty JP, Benacerraf BR, Soeldner JS: FirstTrimester Hemoglobin A I and Risk for Major Malformation and Spontaneous Abortion in Diabetic Pregnancy. Teratology 1989, 39(3):225-31.

24. Hanson U, Persson B, Thunell S: Relationship Between Haemoglobin AIC in Early Type I (Insulin-Dependent) Diabetic Pregnancy and the Occurrence of Spontaneous Abortion and Fetal Malformation in Sweden. Diabetologia 1990, 33(2): $100-4$.

25. CEMACH: Confidential Enquiry into Maternal and Child Health: Pregnancy in Women with Type I and Type 2 Diabetes in 2002-03, England, Wales and Northern Ireland. London 2005.

26. Vaarasmaki MS, Hartikainen A, Anttila M, Pramila S, Koivisto M: Factors Predicting Peri- and Neonatal Outcome in Diabetic Pregnancy. Early Human Development 2000, 59(I):6I-70.

27. Walkinshaw SA: Very Tight Versus Tight Control for Diabetes in Pregnancy. Cochrane Database of Systematic Reviews 2000:CD000226.

28. The Diabetes Control and Complications Trial Research Group: The Effect of Intensive Treatment of Diabetes on the Development and Progression of Long-Term Complications in Insulin-Dependent Diabetes Mellitus. The Diabetes Control and Complications Trial Research Group. New England Journal of Medicine 1993, 329(14):977-86. 
29. Penney GC, Mair G, Pearson DW, Scottish Diabetes in Pregnancy, Group: Outcomes of Pregnancies in Women With Type I Diabetes in Scotland: a National Population-Based Study. BJOG: an International Journal of Obstetrics \& Gynaecology 2003, I I0(3):315-8.

30. Dokken B, Johnson D: The Importance of Reaching Preconception Targets for Glycemic Control in Diabetic Women Archives of Internal Medicine 1998, I 58(I 2): 1299-300.

31. Nielsen GL, Sorensen HT, Nielsen PH, Sabroe S, Olsen J: Glycated Hemoglobin As Predictor of Adverse Fetal Outcome in Type I Diabetic Pregnancies. Acta Diabetologica 1997, 34(3):217-22.

32. Ray JG, O'Brien TE, Chan WS: Preconception Care and the Risk of Congenital Anomalies in the Offspring of Women With Diabetes Mellitus: a Meta-Analysis. QJM 200I, 94(8):435-44.

33. Casele HL, Laifer SA: Factors Influencing Preconception Control of Glycemia in Diabetic Women. Archives of Internal Medicine 1998, I 58( | 2): | 32|-4.

34. Linn T, Bretzel RG: Diabetes in Pregnancy. European Journal of Obstetrics, Gynecology, \& Reproductive Biology 1997, 75(I):37-4I.

\section{Pre-publication history}

The pre-publication history for this paper can be accessed here:

http://www.biomedcentral.com/1471-2393/6/30/prepub

Publish with Biomed Central and every scientist can read your work free of charge

"BioMed Central will be the most significant development for disseminating the results of biomedical research in our lifetime. "

Sir Paul Nurse, Cancer Research UK

Your research papers will be:

- available free of charge to the entire biomedical community

- peer reviewed and published immediately upon acceptance

- cited in PubMed and archived on PubMed Central

- yours - you keep the copyright 